\title{
In vitro Synergy and Time-kill Assessment of Interaction between Kanamycin and Metronidazole against Resistant Bacteria
}

\author{
Olufunmiso O Olajuyigbe ${ }^{1,2 *}$ and Anthony $\mathrm{J}_{\text {Afolayan }}{ }^{2}$ \\ ${ }^{1}$ Biosciences and Biotechnology Department, Babcock University, Ilishan Remo, Ogun State, Nigeria, ${ }^{2}$ Phytomedicine \\ Research Centre, Department of Botany, University of Fort Hare, Alice, 5700, South Africa \\ *For correspondence: Email: funmijuyigbe12@yahoo.com; Tel: +27730562219
}

\begin{abstract}
Purpose: To evaluate the in vitro effects of combining kanamycin and metronidazole against resistant bacteria.

Methods: The influence of combining kanamycin and metronidazole against Gram-positive and Gramnegative bacteria was assessed by agar diffusion, checkerboard and time-kill assays.

Results: The test isolates were highly resistant, with minimum inhibitory concentration (MIC) ranging between 15.63 and >250 $\mu \mathrm{g} / \mathrm{ml}$ for kanamycin, and 15.63 and $125 \mu \mathrm{g} / \mathrm{ml}$ for metronidazole. The antibacterial combinations resulted in drastic decrease in MIC with increased antibacterial activity that indicated synergistic interaction against all the bacteria except Acinetobacter calcaoceuticus UP, Enterobacter cloacae ATCC 13047 and Shigella flexneri KZN. Fractional inhibitory concentration index (FICl) showed synergy ranging from 0.31 to 0.50 , additive interaction with $\mathrm{FICl}$ ranging from 0.53 to 1.25 and absence of antagonistic interaction. Escherichia coli ATCC 25922, Enterococcus faecalis ATCC 29212, Bacillus cereus ATCC 10702, Enterobacter cloacae ATCC 13047, Klebsiella pneumoniae ATCC 10031, Acinetobacter calcoaceuticus UP and Micrococcus luteus were totally eliminated by the antibacterial combinations within $24 \mathrm{~h}$ of incubation. The lack of antagonism between these antibacterial agents in checkerboard and time-kill assays suggest that kanamycin may be effective in both monotherapy and combination therapy.

Conclusion: The study indicates the potential beneficial value of combining kanamycin and metronidazole in the treatment of microbial infections in clinical settings.
\end{abstract}

Keywords: Drug-drug interactions, Synergy, Time-kill, Fractional inhibitory concentration index, Kanamycin, Metronidazole, Microbial resistance

\begin{abstract}
Tropical Journal of Pharmaceutical Research is indexed by Science Citation Index (SciSearch), Scopus, International Pharmaceutical Abstract, Chemical Abstracts, Embase, Index Copernicus, EBSCO, African Index Medicus, JournalSeek, Journal Citation Reports/Science Edition, Directory of Open Access Journals (DOAJ), African Journal Online, Bioline International, Open-J-Gate and Pharmacy Abstracts
\end{abstract}

\section{INTRODUCTION}

Infectious diseases are a significant cause of morbidity and mortality, accounting for approximately $50 \%$ of all deaths in tropical countries [1]. Due to indiscriminate use of antibacterial agents in infectious diseases, multidrug resistance in bacteria has become a great challenge to human health [2]. With the increasing prevalence of multi-drug resistant bacteria, appearances of strains with reduced susceptibility to antibiotics and their inexorable invasion of hospitals and communities, there are increases in health care costs [3], many untreatable bacterial infections and the need to search for new infection-fighting strategies and novel antibacterial agents [4]. 
The use of antimicrobial combinations to achieve synergistic activities against targeted microorganisms is a potential strategy for overcoming bacterial resistance [5]. Theoretically, it is aimed at broadening antimicrobial empirical coverage, improving efficacy against isolates with a minimum inhibitory concentration (MIC) at or approaching the breakpoint for susceptibility as well as preventing the further emergence of resistant organisms [6]. While preventing the emergence of reduced susceptibility, it achieves bactericidal synergy and provides activity against stationaryphase organisms and organisms growing in biofilm. The use of drug combinations is an excellent strategy to avoid drug resistance since different drug target sites are attacked simultaneously. Although previous studies indicated interactions between other aminoglycosides or nitroimidazole (metronidazole) and other antibacterial agents $[7,8]$, combining kanamycin and metronidazole against bacteria of clinical importance has not been reported. This study, therefore, aimed at assessing the effect of combining kanamycin and metronidazole, having different mechanisms of action, against bacteria of clinical relevance.

\section{EXPERIMENTAL}

\section{Bacterial strain}

The bacteria used in this study include Acinetobacter calcoaceuticus UP, Bacillus cereus ATCC 10702, Escherichia coli ATCC 25922, Enterococcus faecalis ATCC 29212, Enterobacter cloacae ATCC 13047, Klebsiella pneumoniae ATCC 10031, Shigella flexneri KZN, Micrococcus luteus, Enterococcus faecalis KZN and Staphylococcus aureus OK2b. They were obtained from the Department of Biochemistry and Microbiology, University of Fort Hare, Alice, South Africa. The antibacterial assays were carried out using Mueller Hinton II Agar (Biolab) and broth.

\section{Antibiotics used in this study}

Stock solutions of Kanamycin (Duchefa) and Metronidazole (Duchefa) were prepared according to the CLSI (Clinical Laboratory Standardization Institute) method or manufacturer's recommendations [9].

\section{Antibiotic susceptibility testing}

Each of the bacterial isolates was standardized using colony suspension method [10]. Each strain's suspension was matched with 0.5
McFarland standards to give a resultant concentration of $1 \times 10^{6} \mathrm{cfu} / \mathrm{ml}$. The antibiotic susceptibility testing was determined by swabbing the Mueller-Hinton agar (MHA) (Oxoids U.K) plates with the resultant saline suspension of each bacterial strain. Wells were then bored into the agar medium with heat sterilized $6 \mathrm{~mm}$ cork borer. The wells were filled with $100 \mu$ of different concentrations $(62.5,125$ and 250 $\mu \mathrm{g} / \mathrm{ml}$ ) of each of the antibiotics without allowing spillage of the solutions onto the agar surfaces. To determine the combinatorial effect of the antibiotics, different solutions containing combined concentrations $(62.5,125$ and 250 $\mu \mathrm{g} / \mathrm{ml}$ ) of kanamycin and metronidazole were used. The plates were allowed to stand for at least 30 min before being incubated at $37^{\circ} \mathrm{C}$ for $24 \mathrm{~h}$. The determinations were done in duplicate. After $24 \mathrm{~h}$ of incubation, the plates were examined for inhibition zones. The diameter of the inhibition zones produced by the respective antibiotic alone and their combinations were measured and interpreted using the CLSI zone diameter interpretative standards [11].

\section{Determination of minimum inhibitory concentration (MIC)}

The minimum inhibitory concentrations (MICs) for the two antibiotics were determined in duplicate by the macrobroth dilution method in Mueller Hinton broth. To determine the MICs of each antibiotic, different concentrations of each of the antibiotics $(0.0019-500) \mu \mathrm{g} / \mathrm{ml}$ were prepared by serial dilution in Mueller Hinton broth. To determine their combined effects, combinations of different concentrations were used in the determination of the MICs of each of the antibiotics were used. The tubes were inoculated with $100 \mu \mathrm{l}$ of each of the adjusted bacterial strains before incubating at $37^{\circ} \mathrm{C}$ for $24 \mathrm{~h}$. Blank Mueller Hinton broth was used as negative control. The MICs were determined in duplicates. The MIC was defined as the lowest concentrations that showed no growth in the Mueller Hinton broth.

\section{Checkerboard assay}

The interactions between the two antibiotics were determined using the checkerboard as previously described [12]. The range of drug concentration used in this assay encompassed the MIC for each antibiotic used in the analysis. The fractional inhibitory concentration (FIC) was derived from the lowest concentrations of the two antibiotics in combination permitting no visible growth of the test organisms in the Mueller Hinton broth after incubation for $24 \mathrm{~h}$ at $37{ }^{\circ} \mathrm{C}$. FIC indices were calculated using the formula, 
$\mathrm{FIC}$ index = (MIC of kanamycin in combination/MIC of kanamycin alone) + (MIC of metronidazole in combination/MIC of metronidazole alone). In this study, synergy was defined as $\sum$ FIC $\leq 0.5$, additivity as $0.5<\sum F I C \leq$ 1 , indifference as $1<\sum \mathrm{FIC} \leq 4$. Concentrations within the FIC panel were such that the MIC of each antibiotic was in the middle of the range of concentrations tested but lower than the MICs of the respective antibiotics.

\section{Determination of rate of kill}

The rates of kill by the combined antibiotics were carried out using a modified plating technique of Eliopoulos and Moellering [13]. The combined antibiotics incorporated into $10 \mathrm{ml}$ of Mueller Hinton broth in McCartney bottles at $1 / 2$ MIC and MIC were inoculated with approximately 1010 cfu/ml further verified by total viable count. Inoculated Mueller Hinton broth without combined antibiotics and uninoculated Mueller Hinton broth incorporated with the combined antibiotics at the test concentrations were included as controls. The tubes were incubated at $37{ }^{\circ} \mathrm{C}$ on an orbital shaker at $120 \mathrm{rpm}$. A 100 $\mu \mathrm{l}$ aliquot was removed from the culture medium at 0,24 and $48 \mathrm{~h}$ for the determination of $\mathrm{cfu} / \mathrm{ml}$ by plating out $25 \mu$ of each of the dilutions in duplicates. After incubating at $37{ }^{\circ} \mathrm{C}$ for $24 \mathrm{~h}$, emergent bacterial colonies were counted, cfu/ml calculated and compared with the counts obtained with antibiotic-free cultures, used as control.

\section{Statistical analysis}

Data, analyzed by SPSS V.16 (Statistical Program for Social Sciences, SPSS Corporation, Chicago, IL), were expressed as means \pm standard deviations (SD) of duplicate determinations. One way analysis of variance (ANOVA) and the Duncan's New Multiple-range test were used to determine the differences among the means. $P<0.05$ was regarded as significant.

\section{RESULTS}

Acinetobacter calcoaceuticus UP and Enterococcus faecalis KZN were highly resistant to kanamycin while other isolates exhibited concentration dependent susceptibility to its varied concentrations. Enterococcus faecalis $\mathrm{KZN}$ was susceptible to the different concentrations of metronidazole while Enterococcus faecalis ATCC 29212, Klebsiella pneumoniae ATCC 10031 and Acinetobacter calcoaceuticus UP were slightly inhibited at the highest concentration. Other isolates were not affected by the different concentrations used.

On combining different concentrations of the two antibiotics, concentration dependent significant synergistic interactions were observed. The resultant zones of inhibition from the antibacterial combinations were wider than those obtained from the antibacterial activities of each of the antibiotics (Table 1). Though the bacteria showed varied resistance to both antibiotics, resistant colonies were not isolated within the zones of inhibition and fuzzy zones were not found around the edges of the zones of inhibition.

From the macrobroth assay, the test isolates were highly resistant to the two antibiotics by exhibiting minimum inhibitory concentrations (MICs) ranging between 15.625 and $>250 \mu \mathrm{g} / \mathrm{ml}$ for kanamycin and 15.625 - $125 \mu \mathrm{g} / \mathrm{ml}$ for metronidazole. On combining the two antibiotics against these bacteria, the MICs of both antibiotics were drastically reduced in the range between $1 / 2$ MIC and 1/8 MIC with a simultaneous increase in the antibacterial activity of the combined antibiotics (Table 2). The results of both assays were complementary. The significant reduction in the MICs and the observed increase in the inhibition zones from the combined antibiotics showed that the resultant effect of combining these two antibiotics was synergy.

In the checkerboard assay, antibacterial combinations showed synergistic interaction against most of the bacteria except Acinetobacter calcoaceuticus UP, Enterobacter claoacae ATCC 13047 and Shigella flexneri KZN. While the fractional inhibitory concentration indices (FICls) showed synergy ranging from 0.3125 - 0.5, an additive interaction was indicated with $\mathrm{FICl}$ ranging between 0.5313 and 1.25 and no antagonism was recorded from the antibacterial combinations.

The time-kill assay results presented as changes in the $\log _{10} \mathrm{cfu} / \mathrm{ml}$ of viable colonies showed that the antibacterial combinations exhibited a significant bactericidal activity. The bactericidal activity was defined as being equal to $3 \log _{10}$ $\mathrm{cfu} / \mathrm{ml}$ or greater reduction in the viable colony count relative to the initial inoculum [14]. Escherichia coli ATCC 25922, Enterococcus faecalis ATCC 29212, Bacillus cereus ATCC 10702, Enterobacter cloacae ATCC 13047 and Micrococcus luteus were completely annihilated by the combination of kanamycin and 
Table 3: In vitro time-kill activity of Kanamycin/metronidazole combinations at $1 / 2 \times \mathrm{MIC}\left(\mathrm{MIC}_{50 \%}\right)$ and $\mathrm{MIC}$ against test bacteria

\begin{tabular}{|c|c|c|c|c|c|c|}
\hline \multirow[b]{3}{*}{ Test bacterium } & \multicolumn{6}{|c|}{$\begin{array}{l}\left.\text { Reduction in bacterial counts ( } \log _{10} \mathrm{CFU} / \mathrm{ml}\right) \text { for the combined } \\
\text { antibiotics }\end{array}$} \\
\hline & \multicolumn{4}{|c|}{$M I C_{50 \%}$} & \multicolumn{2}{|c|}{ MIC } \\
\hline & $0(h)$ & 24 (h) & $48(h)$ & 0 (h) & 24 (h) & $48(h)$ \\
\hline Escherichia coli ATCC 25922 & 7.18 & 0 & 0 & 6.90 & 0 & 0 \\
\hline Enterococcus faecalis ATCC 29212 & 8.90 & 0 & 0 & 8.91 & 0 & 0 \\
\hline Bacillus cereus ATCC 10702 & 7.62 & 0 & 0 & 7.26 & 0 & 0 \\
\hline Enterobacter cloacae ATCC 13047 & 12.15 & 0 & 0 & 12.38 & 0 & 0 \\
\hline Klebsiella pneumoniae ATCC 10031 & 11.51 & 5.78 & 5.97 & 11.61 & 0 & 0 \\
\hline Acinetobacter calcaoceuticus UP & 12.70 & 3.45 & 3.94 & 12.81 & 0 & 0 \\
\hline Shigella flexneri KZN & 12.43 & 3.92 & 4.32 & 12.51 & 3.86 & 3.96 \\
\hline Micrococcus luteus & 11.93 & 0 & 0 & 11.99 & 0 & 0 \\
\hline Enterococcus faecalis KZN & 10.42 & 4.11 & 4.54 & 11.15 & 3.90 & 4.28 \\
\hline Staphylococcus aureus $\mathrm{OK}_{2 \mathrm{~b}}$ & 9.38 & 5.13 & 5.27 & 9.66 & 3.94 & 4.08 \\
\hline
\end{tabular}

metronidazole at $1 / 2$ MICs. These bacteria along with Klebsiella pneumoniae ATCC 10031 and Acinetobacter calcoaceuticus UP were totally killed by the antibacterial combination at the MICs within $24 \mathrm{~h}$ of incubation. Shigella flexneri $\mathrm{KZN}$, Enterococcus faecalis KZN and Staphylococcus aureus OK2b were not totally inhibited at the combined MICs despite the degree of synergism observed because each of the isolates exhibited a very high level of resistance to either or both antibiotics.

Average log reduction in viable cell count in timekill assay for Klebsiella pneumoniae ATCC 10031, Acinetobacter calcoaceuticus UP, Shigella flexneri KZN, Enterococcus faecalis $\mathrm{KZN}$ and Staphylococcus aureus OK2b not totally eliminated, however, ranged between 3.4472 $\log _{10}$ to $5.7782 \log _{10} \mathrm{cfu} / \mathrm{ml}$ after $24 \mathrm{~h}$ of incubation with the combined antibiotics at the $1 / 2$ MIC and MIC values (Table 3). A post-antibiotic treatment bioassay done after $48 \mathrm{~h}$ showed that all isolates not totally inhibited within $24 \mathrm{~h}$ incubation period had an increase in $\mathrm{cfu} / \mathrm{ml}$.

\section{DISCUSSION}

Due to the frequent development of resistance during monotherapy treatment of infected patients, multiple combinations of antibacterial agents are being proposed [15]. These were to effectively treat mixed and severe infections, enhance antibacterial activity, reduce the time needed for long-term antimicrobial therapy and prevent the emergence of resistant microorganisms [16] because drug combinations are characterized by an increased activity and tolerability compared to that of monotherapy and those used to increase the killing of single-drug resistant strains or mutants.
In this study, the checkerboard method demonstrated synergy between kanamycin and metronidazole for the majority of the strains while antagonism was not observed. The combined antibiotics indicated ability to improve the bactericidal effects of each other on both Gramnegative and Gram-positive bacteria. This is in agreement with previous reports on interaction between aminoglycosides and other antibacterial agents [17]. Their combination in chemotherapy could decrease resistance development, broaden antibacterial spectrum and encourage synergistic antibacterial activity [18].

As determined by Eliopoulos and Moellering [13], antibiotic combinations that reduced the original inocula by $\geq 2 \log _{10} \mathrm{cfu} / \mathrm{ml}$ were considered synergy while antagonism is $a<2 \log _{10}$ change in cfu/ml when compared with the activity of the individual antibiotic after $24 \mathrm{~h}$ incubation period. The time-kill assay confirmed the synergy between kanamycin and metronidazole as indicated by the checkerboard assay. This synergy that resulted in enhanced antibacterial effects from antibiotics having different mechanisms of action could have resulted from the formation of a complex compound with enhanced antibacterial activity. Since kanamycin prevents bacteria from synthesizing proteins by binding to $16 \mathrm{~S}$ rRNA of $30 \mathrm{~S}$ subunit and metronidazole is reduced to cytotoxic polar compounds able to cause DNA strand breakage, DNA helix and nucleic acid destabilization in bacteria [19], the synergy of the antibacterial combination could be a means of achieving effective therapy at a reduced cost with a drastic reduction or loss of vestibular and auditory toxicity often associated with the aminoglycosides While the lack of antagonism between the antibiotics suggested that kanamycin or metronidazole may be effective in monotherapy and combination therapy, this synergy will reduce the dose of each drug in the 
Table 1: Mean zone of inhibition $( \pm 1.0 \mathrm{~mm}$ ) produced by each antibiotic and their combinations at various concentrations

\begin{tabular}{|c|c|c|c|c|c|c|c|c|c|}
\hline \multicolumn{10}{|c|}{ ZONE OF INHIBITION ( $\pm 1.0 \mathrm{~mm})$} \\
\hline & \multicolumn{3}{|c|}{ Kanamycin alone $(\mu g / m I)$} & \multicolumn{3}{|c|}{ Metronidazole $(\mu \mathrm{g} / \mathrm{m} /)$} & \multicolumn{3}{|c|}{ Kan-Met combinations $(\mu \mathrm{g} / \mathrm{m} /)$} \\
\hline & 250 & 125 & 62.5 & 250 & 125 & 62.5 & $250 / 250$ & $125 / 125$ & $62.5 / 62.5$ \\
\hline \multicolumn{10}{|l|}{ Test bacterium } \\
\hline Escherichia coli ATCC 25922 & $25 \pm 1.00^{c}$ & $20 \pm 0.58^{\mathrm{d}}$ & $18 \pm 0.58^{\dagger}$ & $0 \pm 0.00^{9}$ & $0 \pm 0.00^{9}$ & $0 \pm 0.00^{9}$ & $29 \pm 1.00^{\mathrm{a}}$ & $26 \pm 1.00^{b}$ & $20 \pm 0.58^{\mathrm{d}}$ \\
\hline Enterococcus faecalis ATCC 29212 & $26 \pm 0.58^{\mathrm{b}}$ & $24 \pm 0.58^{c}$ & $21 \pm 0.58^{a}$ & $16 \pm 0.58^{\mathrm{e}}$ & $0 \pm 0.00^{\top}$ & $0 \pm 0.00^{\top}$ & $27 \pm 1.53^{a}$ & $24 \pm 1.53^{c}$ & $21 \pm 0.58^{a}$ \\
\hline Bacillus cereus ATCC 10702 & $27 \pm 0.58^{\mathrm{b}}$ & $24 \pm 0.58^{a}$ & $22 \pm 0.58^{\top}$ & $0 \pm 0.00^{g}$ & $0 \pm 0.00^{g}$ & $0 \pm 0.00^{9}$ & $29 \pm 0.58^{a}$ & $25 \pm 0.58^{c}$ & $23 \pm 0.58^{e}$ \\
\hline Enterobacter cloacae ATCC 13047 & $22 \pm 1.00^{\mathrm{b}}$ & $20 \pm 0.58^{c}$ & $19 \pm 0.58^{d}$ & $0 \pm 0.00^{\dagger}$ & $0 \pm 0.00^{\dagger}$ & $0 \pm 0.00^{\dagger}$ & $25 \pm 0.00^{a}$ & $22 \pm 0.58^{b}$ & $20 \pm 0.58^{c}$ \\
\hline Klebsiella pneumoniae ATCC 10031 & $28 \pm 0.58^{b}$ & $25 \pm 0.58^{d}$ & $21 \pm 0.58^{\dagger}$ & $13 \pm 0.58^{\mathrm{g}}$ & $0 \pm 0.00^{\mathrm{h}}$ & $0 \pm 0.00^{\mathrm{h}}$ & $29 \pm 0.58^{a}$ & $27 \pm 0.58^{c}$ & $22 \pm 0.58^{e}$ \\
\hline Acinetobacter calcaoceuticus UP & $0 \pm 0.00^{\mathrm{e}}$ & $0 \pm 0.00^{\mathrm{e}}$ & $0 \pm 0.00^{\mathrm{e}}$ & $14 \pm 0.58^{d}$ & $0 \pm 0.00^{\mathrm{e}}$ & $0 \pm 0.00^{\mathrm{e}}$ & $26 \pm 0.58^{a}$ & $24 \pm 0.58^{b}$ & $20 \pm 0.58^{c}$ \\
\hline Shigella flexneri KZN & $28 \pm 0.58^{\mathrm{a}}$ & $25 \pm 0.58^{c}$ & $23 \pm 0.58^{a}$ & $0 \pm 0.00^{\dagger}$ & $0 \pm 0.00^{\dagger}$ & $0 \pm 0.00^{\top}$ & $28 \pm 1.53^{a}$ & $26 \pm 0.58^{\mathrm{b}}$ & $22 \pm 0.58^{\mathrm{e}}$ \\
\hline Micrococcus luteus & $24 \pm 0.58^{c}$ & $21 \pm 0.58^{a}$ & $20 \pm 0.58^{\mathrm{e}}$ & $0 \pm 0.00^{\top}$ & $0 \pm 0.00^{\top}$ & $0 \pm 0.00^{\top}$ & $28 \pm 1.00^{a}$ & $25 \pm 0.58^{\mathrm{D}}$ & $21 \pm 0.58^{a}$ \\
\hline Enterococcus faecalis $\mathrm{KZN}$ & $0 \pm 0.00^{\mathrm{g}}$ & $0 \pm 0.00^{\mathrm{g}}$ & $0 \pm 0.00^{g}$ & $20 \pm 0.58^{a}$ & $19 \pm 1.00^{\mathrm{e}}$ & $14 \pm 0.58^{\mathrm{t}}$ & $31 \pm 0.58^{a}$ & $28 \pm 1.53^{\mathrm{b}}$ & $23 \pm 0.58^{c}$ \\
\hline Staphylococcus aureus $\mathrm{OK}_{2 \mathrm{~b}}$ & $28 \pm 0.58^{\mathrm{a}}$ & $24 \pm 0.58^{c}$ & $22 \pm 0.58^{d}$ & $0 \pm 0.00^{\dagger}$ & $0 \pm 0.00^{\dagger}$ & $0 \pm 0.00^{\dagger}$ & $26 \pm 0.58^{b}$ & $24 \pm 0.58^{c}$ & $20 \pm 0.58^{e}$ \\
\hline
\end{tabular}

Note: The mean inhibition zones with different superscript along the same row are significantly different $(p<0.05)$

Table 2: Fractional inhibitory concentration values for the antibiotics alone and their combinations against resistant bacterial isolates

\begin{tabular}{|c|c|c|c|c|c|c|c|}
\hline \multirow[b]{2}{*}{ Test bacterium } & \multicolumn{3}{|c|}{ Minimum inhibitory concentration $(\mu \mathrm{g} / \mathrm{ml})$} & \multicolumn{4}{|c|}{ Fractional inhibitory concentration index } \\
\hline & Kanamycin & Metronidazole & KAN-MET & FICI Kan & FICI Met & $\mathrm{FICl}$ & Remarks \\
\hline Escherichia coli ATCC 25922 & 125 & 31.25 & $15.63 / 7.81$ & 0.13 & 0.25 & 0.38 & Synergistic \\
\hline Enterococcus faecalis ATCC 29212 & 125 & 31.25 & $15.63 / 7.81$ & 0.13 & 0.25 & 0.38 & Synergistic \\
\hline Bacillus cereus ATCC 10702 & 125 & 31.25 & $7.81 / 7.81$ & 0.06 & 0.25 & 0.31 & Synergistic \\
\hline Enterobacter cloacae ATCC 13047 & 62.5 & 31.25 & $15.63 / 15.63$ & 0.25 & 0.5 & 0.75 & Additive \\
\hline Klebsiella pneumoniae ATCC 10031 & 31.25 & 31.25 & $7.81 / 7.81$ & 0.25 & 0.25 & 0.5 & Synergistic \\
\hline Acinetobacter calcaoceuticus UP & $>250$ & 15.63 & 7.81/7.81 & 0.03 & 0.5 & 0.53 & Additive \\
\hline Shigella flexneri KZN & 15.63 & 62.25 & 15.63/15.63 & 1.0 & 0.25 & 1.25 & Indifference \\
\hline Micrococcus luteus & 250 & 31.25 & $15.63 / 7.81$ & 0.06 & 0.25 & 0.31 & Synergistic \\
\hline Enterococcus faecalis KZN & $>250$ & 62.5 & $15.63 / 15.63$ & 0.06 & 0.25 & 0.31 & Synergistic \\
\hline Staphylococcus aureus $\mathrm{OK}_{2 \mathrm{~b}}$ & 62.5 & 125 & $15.63 / 15.63$ & 0.25 & 0.125 & 0.38 & Synergistic \\
\hline
\end{tabular}


combination and prevent the development of bacterial resistance [20].

Although bactericidal drugs prevent the emergence of resistant mutants by killing the microorganism [21] while synergy and bactericidal therapy could be achieved as long as the organism does not exhibit high-level resistance to aminoglycoside [22], it is evident, from this study, the highly resistant bacteria with MIC ranging between 15.625 and $>250 \mu \mathrm{g} / \mathrm{ml}$ for kanamycin were killed by its combination with metronidazole to which the MICs were between 15.625 and $125 \mu \mathrm{g} / \mathrm{mL}$ for the different isolates.

The regrowth of Shigella flexneri KZN, Enterococcus faecalis KZN and Staphylococcus aureus OK2b can be attributed to the preferential killing of the susceptible subpopulations allowing the selective increase of the resistant subpopulation of each of these resistant strains after $48 \mathrm{~h}$ incubation. Further treatment or subsequent doses of the antibacterial combinations would be sufficient to eliminate the resistant subpopulation.

\section{CONCLUSION}

Combining existing antimicrobial agents such as kanamycin and metronidazole can improve delivery of safe and cost effective patient care in an era where research into discovery of new agents is limited and expensive. In clinical settings, this study emphasizes the potential beneficial value of combining kanamycin and metronidazole for treating seriously ill patients with infections caused by the pathogens tested, especially in the absence of other therapeutic options. Future studies in in vivo infection models would provide a better understanding of the therapeutic potential and safety of kanamycinmetronidazole combinations.

\section{REFERENCES}

1. Khosravi A, Behzadi A. Evaluation of the antibacterial activity of the seed hll of Quercus barantii on some gram-negative bacteria. Pak J Med Sci 2006; 22: 429-432.

2. Peters NK, Dixon DM, Holland SM, Fauci AS. The research agenda of the National Institute of Allergy and Infectious Diseases for Antimicrobial Resistance. $J$ Infect Dis 2008; 197(8): 1087-1093.

3. Gums JG. Assessing the impact of antimicrobial resistance. Am J Health Syst Pharm 2002; 59(8Suppl.3): S4-6.

4. Ymele-Leki P, Cao S, Sharp J, Lambert KG, McAdam AJ, Husson RN, Tamayo G, Clardy J, Watnick PI. A high- throughput screen identifies a new natural product with broad-spectrum antibacterial activity. PLoS One 2012; 7(2): e31307.

5. Allen GP, Cha R, Rybak MJ. In vitro activities of Quinupristin-Dalfopristin and Cefepime, alone and in combination with various antimicrobials, against multidrug resistant Staphylococci and Enterococci in an in vitro pharmacodynamic model. Antimicrob. Agents Chemother 2002; 46(8): 2606- 2612.

6. Walsh TR, Howe RA. The prevalence and mechanisms of vancomycin resistance in Staphylococcus aureus. Ann Rev Microbiol 2002; 56: 657-675.

7. Kelesidis $T$, Karageorgopoulos DE, Kelesidis I, Falagas ME. Tigecycline for the treatment of multidrug-resistant Enterobacteriaceae: a systematic review of the evidence from microbiological and clinical studies. J Antimicrob Chemother 2008; 62: 895-904.

8. Levine A, Turner D. Combined azithromycin and metronidazole therapy is effective in inducing remission in pediatric Crohn's disease. J Crohn's Colitis 2011; 5(3): 222-226.

9. Richard S, Lynn SM, Avery CG. Antimicrobial susceptibility testing protocols. CRC Press, Taylor and Francis Group; New York, 2007.

10. EUCAST, European Committee on Antimicrobial Susceptibility Testing, EUCAST disk diffusion method for antimicrobial susceptibility testing, 2012; Version 2.1. pp. 1- 17.

11. CLSI Clinical and Laboratory Standard Institute. Performance standards for Antimicrobial Susceptibility Testing Eighteenth informational supplement. M100 S18 2008; 28(1): 46-52.

12. Petersen PJ, Labthavikul $P$, Jones $C H$, Bradford PA. In vitro antibacterial activities of tigecycline in combination with other antimicrobial agents determined by chequerboard and time-kill kinetic analysis. J Antimicrob Chemother 2006; 57: 573-576.

13. Eliopoulos GM, Moellering RC. Antimicrobial combinations, In V. Lorain [ed.], Antibiotics in laboratory Medicine, 4th ed. The Williams \& Wilkins Co., Baltimore, Md. 1996; 330-396.

14. Scheetz MH, Qi C, Warren JR, Postelnick MJ, Zembower $T$, Obias A, Noskin GA. In vitro activities of various antimicrobials alone and in combination with tigecycline against carbapenem intermediate or resistant Acinetobacter baumannii. Antimicrob Agents Chemother 2007; 51: 1621-1626.

15. El Solh AA, Alhajhusain A. Update on the treatment of Pseudomonas aeruginosa pneumonia. J Antimicrob Chemother 2009; 64: 229-238.

16. Levinson W, Jawetz E. Medical microbiology and immunology: Examination and board review. International 7th ed., Lange Medical Books/McGrawHill, New York, 2002.

17. Schwebke JR, Desmond RA. A randomized trial of the duration of therapy with metronidazole plus or minus 
azithromycin for treatment of symptomatic bacterial vaginosis. Clin Infect Dis 2007; 44(2): 213-219.

18. den Hollander J, Mouton J. The predictive value of laboratory tests for efficacy of antibiotic combination therapy. p. 103-127. In Nightingale C, Ambrose P, Drusano G, Murakawa T. (ed.), Antimicrobial pharmacodynamics in theory and clinical practice, 2nd ed. Informa Healthcare, New York, NY, 2007.

19. Tocher JH, Edwards DI. Evidence for the direct interaction of reduced metronidazole derivatives with DNA bases. Biochem Pharmacol 1994; 48: 1089.
20. Wu YL, Scott EM, Po ALW, Tariq VN. Ability of azlocillin and tobramycin in combination to delay or prevent resistance development in Pseudomonas aeruginosa. J Antimicrob Chemother 1999; 44: 389-392.

21. Stratton CW. Dead bugs don't mutate: susceptibility issues in the emergence of bacterial resistance. Emerg Infect Dis 2003; 9: 10-16.

22. Arias CA, Murray BE. Emergence and management of drug-resistant enterococcal infections. Expert Rev Anti-Infect Ther 2008; 6: 637-655. 